\title{
Kidney disease and care among First Nations people with diabetes in Ontario: a population-based cohort study
}

\author{
Danielle M. Nash MSc PhD, Jade S. Dirk BSc, Eric McArthur MSc, Michael E. Green MD MPH, \\ Baiju R. Shah MD PhD, Jennifer D. Walker PhD, Mary Beaucage, Carmen R. Jones BA, \\ Amit X. Garg MD PhD
}

See related research article at www.cmajopen.ca/lookup/doi/10.9778/cmajo.20190096

\section{Abstract}

Background: End-stage kidney disease is a serious complication of diabetes. We describe the prevalence of chronic kidney disease, prevalence and incidence of end-stage kidney disease and quality of care of early-stage chronic kidney disease for First Nations people with diabetes compared to other Ontarians with diabetes.

Methods: We conducted a retrospective cohort study in Ontario using linked administrative data at ICES. We included adults with incident diabetes between 1994 and 2014, and used laboratory values to identify kidney disease and quality indicators for care for early-stage disease. We compared measures in First Nations people to those in other people in Ontario, and used direct age and sex standardization. We used Cox proportional hazards regression to compare the incidence of end-stage kidney disease between groups.

Results: Our study included 21968 First Nations people with diabetes. The age- and sex-standardized prevalence of chronic kidney disease was higher for First Nations people than for other Ontarians (20.7\% v. $18.4 \%$ ), as was the prevalence of end-stage kidney disease $(2.9 \%$ v. $1.0 \%)$. The incidence of end-stage kidney disease was higher among First Nations people than among other people in Ontario (9.3 v. 4.7 events per 10000 person-years; age- and sex-adjusted hazard ratio 2.23, 95\% confidence interval 1.72-2.89). The 2 groups were similarly likely to receive recommended medications, but First Nations people were less likely to receive laboratory tests for their kidney disease.

Interpretation: Despite receiving similar quality of care for early-stage kidney disease, First Nations people with diabetes had higher rates of end-stage kidney disease than other Ontarians. Further research is needed to better understand contributing factors to help inform future interventions.

bout 2.4 million Canadians are living with diabetes. ${ }^{1}$ A serious complication of diabetes is end-stage kidney disease, which has a worse outcome than many advanced cancers and is fatal without life-sustaining treatments such as dialysis or kidney transplantation. ${ }^{2}$ In 2017, around 39000 Canadians were living with end-stage kidney disease. $^{3}$ In Ontario primary care, it is a priority to detect kidney disease early and slow the progression to end-stage kidney disease. ${ }^{4}$

First Nations people generally have higher rates and an earlier onset of end-stage kidney disease compared to other Canadians. ${ }^{5-8}$ However, the prevalence of kidney disease among First Nations people with diabetes in Ontario is not well known. Furthermore, there are few data on the quality of care for early-stage kidney disease delivered by Ontario pri- mary care providers to First Nations people with diabetes and chronic kidney disease. Our study objectives were to describe the prevalence of chronic kidney disease, the prevalence and incidence of end-stage kidney disease, the average distance travelled for in-centre hemodialysis treatment and the quality of care for early-stage kidney disease for First Nations people with diabetes compared to other people in Ontario.

\section{Competing interests: None declared.}

This article has been peer reviewed.

Correspondence to: Danielle Nash, Danielle.nash @ices.on.ca CMAJ Open 2019. DOI:10.9778/cmajo.20190164 


\section{Methods}

\section{Study design and research setting}

Ontario - Canada's most populous province, with over 14 million residents - has universal access to hospital and physician care, including laboratory tests, that is managed both provincially (for the majority of Ontarians) and federally (for specific populations, including First Nations people residing in more remote communities). We conducted a retrospective population-based cohort study using provincial health care administrative data at ICES, a not-for-profit research institute. We followed reporting guidelines for observational studies using routinely collected health care data. ${ }^{9}$

We used a community-based participatory research approach following principles of ownership, control, access and possession (OCAP, a registered trademark of the First Nations Information Governance Centre). ${ }^{10}$ We used data from the Indian Register, which is owned and controlled by First Nations people and held at ICES as a data custodian. This database includes information on demographic characteristics, band transfers and deaths of all Status (Registered) First Nations people recognized under the Indian Act. ${ }^{11}$ Additional details are available elsewhere. ${ }^{12,13}$

\section{Data sources}

We used 11 databases at ICES linked by means of unique encoded identifiers to identify Status First Nations people (Indian Register) and to ascertain information on diabetes diagnosis (Ontario Diabetes Database), hospital admissions and emergency department visits (Canadian Institute for Health Information's Discharge Abstract Database, Same Day Surgery Database and National Ambulatory Care Reporting System), physician information including billings (Ontario Health Insurance Plan database and ICES Physician database), treatments for end-stage kidney disease (Canadian Organ Replacement Register), outpatient test results (Ontario Laboratories Information System, which includes complete information for all community-based laboratory tests but not all hospital-based tests), outpatient prescriptions (Ontario Drug Benefit database) and vital status and demographic information (Registered Persons Database). For more information on these data sources, see Slater and colleagues. ${ }^{13}$

\section{Cohort assembly}

We included all Ontario residents with a diabetes diagnosis between Apr. 1, 1994, and Mar. 31, 2014 who were alive as of Sept. 30, 2015. We used this cohort to assess the prevalence of chronic kidney disease and end-stage kidney disease.

To assess the quality of care for early-stage kidney disease, we created 4 subcohorts for the denominators of interest using laboratory values from Apr. 1, 2011, until Sept. 30, 2014 (allowing 1-yr follow-up to Sept. 30, 2015) (Appendix 1, available at www.cmajopen.ca/content/7/4/706/suppl/DC1). For each subcohort, we excluded people with previous receipt of long-term dialysis or a kidney transplant, as we were interested in assessing care for early-stage kidney disease only (i.e., pre-end-stage kidney disease).
To identify the incidence of end-stage kidney disease, we created a fifth subcohort of people with a diabetes diagnosis between Apr. 1, 2002, and Dec. 31, 2014 - to allow at least 1 year of follow-up to Dec. 31, 2015 — with no evidence of prior end-stage kidney disease.

\section{Measures}

To identify the prevalence and severity of chronic kidney disease, we identified patients with at least 1 outpatient serum creatinine value and random urine albumin-to-creatinine ratio value in the 3 years before Sept. 30, 2015 and used the most recent value for both measures. We used the Chronic Kidney Disease Epidemiology Collaboration equation to calculate estimated glomerular filtration rate, and, since we had no information on race, we assumed all patients in the Ontario population other than First Nations people ("other people in Ontario") to be nonblack in the equation (less than $5 \%$ of the Ontario population is black). ${ }^{14,15}$ Based on the most recent values for estimated glomerular filtration rate and urine albuminto-creatinine ratio, we used the chronic kidney disease classification (i.e., heat map) from Kidney Disease: Improving Global Outcomes Clinical Practice Guidelines. ${ }^{16} \mathrm{We}$ also identified kidney disease based on estimated glomerular filtration rate staging alone among those with at least 1 serum creatinine value, since testing of the urine albumin-to-creatinine ratio is not done as routinely as serum creatinine testing. We defined chronic kidney disease as at least 1 estimated glomerular filtration rate value less than $60 \mathrm{~mL} / \mathrm{min}$ per $1.73 \mathrm{~m}^{2}$.

To measure the prevalence of end-stage kidney disease, we identified people with an estimated glomerular filtration rate less than $15 \mathrm{~mL} / \mathrm{min}$ per $1.73 \mathrm{~m}^{2}$ in the 3 years before Sept. 30, 2015, or evidence of long-term dialysis or kidney transplantation from the earliest date in our databases (up to 27 yr prior). For patients receiving dialysis, we identified the most recent modality as in-centre hemodialysis or home dialysis (home hemodialysis/peritoneal dialysis). Among patients receiving in-centre hemodialysis, we measured great-circle distance (the shortest distance between 2 points on a sphere) in kilometres to their dialysis facility from their home residence using postal codes. Less than $2 \%$ of patients had missing postal codes and were not included in this analysis. We identified the incidence of end-stage kidney disease as initiation of long-term dialysis or kidney transplantation any time after diabetes diagnosis, and censored for death or end of follow-up.

To assess quality of care, we used consensus-based quality indicators for early-stage chronic kidney disease, ${ }^{17,18}$ which included receipt of kidney function tests, prescription medication use (e.g., angiotensin-converting-enzyme [ACE] inhibitors, angiotensin II receptor blockers [ARBs] or avoidance of nonsteroidal anti-inflammatory drugs) and nephrologist referral (Appendix 2, available at www.cmajopen.ca/content/7/4/ E706/suppl/DC1). The nephrology indicators were based on the Ontario Renal Network's KidneyWise Toolkit, ${ }^{18}$ and the remaining indicators were identified through a modified Delphi panel. ${ }^{17}$ We restricted our assessment of prescription medication use to people aged 65 years or more, who have 
provincial drug coverage. Specialist referrals are not captured in our data sources, so we used nephrologist visits as a proxy.

\section{Analysis}

We conducted all analyses using SAS version 9.4 (SAS Institute) at ICES Western in London, Ontario. All measures were described for First Nations people and compared to those for all other people in Ontario. We used direct standardization based on other people in Ontario to estimate ageand sex-standardized prevalence estimates for First Nations people. ${ }^{19,20} \mathrm{We}$ calculated proportions for binary and categorical measures, and medians (25th, 75 th percentiles) to describe distance to dialysis facilities. We estimated probability of endstage kidney disease during follow-up using Kaplan-Meier survival curves. We also compared the incidence of end-stage kidney disease between First Nations people and other people in Ontario using a Cox proportional hazards regression model, adjusting for age and sex. Two-sided $p$ values $<0.05$ were considered statistically significant.

\section{Ethics approval}

In addition to Ontario First Nations data-governance processes, our project was approved by the research ethics boards at Queen's University and Laurentian University. As ICES is a designated prescribed entity under Section 45 of the Ontario Personal Health Information Protection Act, participant informed consent was not required for this study.

\section{Results}

There were 21968 First Nations people and 1303177 other people in Ontario with a diabetes diagnosis between Apr. 1, 1994, and Mar. 31, 2014 who were alive as of Sept. 30, 2015 (Table 1). Cohort assembly diagrams are given in Appendix 1.

\section{Prevalence of kidney disease}

Among patients with at least 1 serum creatinine value, the age- and sex-standardized prevalence of chronic kidney disease was higher for First Nations people (20.7\%) than for other people in Ontario (18.4\%) (Table 2). The age- and sexstandardized proportion at very high risk for kidney-diseaserelated adverse events was $10.8 \%$ for First Nations people and $6.5 \%$ for other Ontarians. The age- and sex-standardized prevalence of end-stage kidney disease (based on estimated glomerular filtration rate $<15 \mathrm{~mL} / \mathrm{min}$ per $1.73 \mathrm{~m}^{2}$ and treatment with dialysis or transplantation) was $2.9 \%$ for First Nations people and $1.0 \%$ for other people in Ontario. First Nations people were more likely than other people in Ontario to be receiving long-term dialysis ( $1.7 \% \mathrm{v}$. $0.5 \%)$.

Among people receiving long-term dialysis, the age- and sex-standardized proportion receiving in-centre hemodialysis as opposed to home dialysis was higher in First Nations people than in other people in Ontario $(87.1 \%$ v. $80.0 \%$ ) (Appendix 3, Supplemental Figure S1, available at www.cmajopen.ca/content/7/4/E706/suppl/DC1). First Nations people receiving in-centre hemodialysis had to travel farther to receive dialysis than other people in the province (median [25th, 75th percentiles] $11[4,41] \mathrm{km} \mathrm{v.} 7$ $[3,16] \mathrm{km}$ ) (Appendix 3, Supplemental Figure S2).

\section{Incidence of end-stage kidney disease}

The incidence of end-stage kidney disease following diabetes onset was higher for First Nations people than for other people in Ontario (9.3 v. 4.7 events per 10000 person-years; age- and sex-adjusted hazard ratio 2.23 , 95\% confidence interval 1.72 2.89) (Figure 1). The median (25th, 75 th percentiles) age at onset of end-stage kidney disease was $52(43,61)$ years for First Nations people and $60(48,70)$ years for other people in Ontario.

\section{Quality of care for early-stage kidney disease}

Among patients who had an initial estimated glomerular filtration rate less than $60 \mathrm{~mL} / \mathrm{min}$ per $1.73 \mathrm{~m}^{2}$, similar proportions of First Nations people and other people in Ontario received a repeat serum creatinine test $(44.4 \%$ v. $46.5 \%, p=$ $0.3)$, but a lower proportion of First Nations people received a follow-up albumin-to-creatinine ratio test within 6 months (18.0\% v. 23.8\%, $p=0.001$ ) (Table 3). Among patients with chronic kidney disease, a lower proportion of First Nations people than other people in Ontario received regular kidney function monitoring $(73.8 \%$ v. $79.8 \%$ for serum creatinine monitoring, $p=0.002 ; 41.1 \%$ v. $50.0 \%$ for albumin-tocreatinine ratio monitoring, $p<0.001)$.

Most patients with chronic kidney disease were not prescribed a nonsteroidal anti-inflammatory drug for longer than

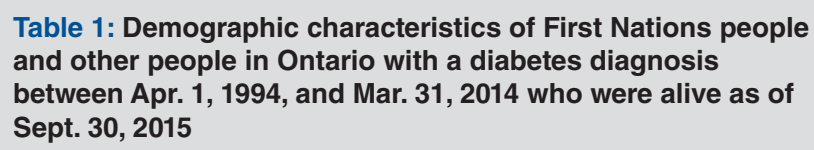

\begin{tabular}{|c|c|c|}
\hline \multirow[b]{2}{*}{ Characteristic } & \multicolumn{2}{|c|}{ No. (\%) of people* } \\
\hline & $\begin{array}{c}\text { First Nations } \\
\text { people } \\
n=21968\end{array}$ & $\begin{array}{c}\text { Other people in } \\
\text { Ontario } \\
n=1303177\end{array}$ \\
\hline \multicolumn{3}{|l|}{ Sex } \\
\hline Male & 10172 (46.3) & 676059 (51.9) \\
\hline Female & 11796 (53.7) & $627118(48.1)$ \\
\hline \multicolumn{3}{|l|}{ Age, yr } \\
\hline$\leq 19$ & $254(1.2)$ & $10141(0.8)$ \\
\hline $20-34$ & $1414(6.4)$ & 38549 (3.0) \\
\hline $35-49$ & $5154(23.5)$ & $170143(13.1)$ \\
\hline $50-64$ & 8938 (40.7) & $448351(34.4)$ \\
\hline $65-74$ & $4133(18.8)$ & $333836(25.6)$ \\
\hline $75-105$ & $2075(9.4)$ & 302157 (23.2) \\
\hline \multicolumn{3}{|l|}{$\begin{array}{l}\text { Age at diabetes } \\
\text { diagnosis, yr }\end{array}$} \\
\hline Mean \pm SD & $44.2 \pm 13.8$ & $52.6 \pm 14.7$ \\
\hline Median (IQR) & $45(35-53)$ & $53(44-63)$ \\
\hline
\end{tabular}




\begin{tabular}{|c|c|c|c|}
\hline \multirow[b]{2}{*}{ Variable } & \multicolumn{2}{|c|}{ First Nations people } & \multirow[b]{2}{*}{$\begin{array}{c}\text { Other people in } \\
\text { Ontario, prevalence, } \\
\text { no. (\%) }\end{array}$} \\
\hline & $\begin{array}{l}\text { Crude prevalence, } \\
\text { no. }(\%)\end{array}$ & $\begin{array}{c}\text { Age- and } \\
\text { sex-standardized } \\
\text { prevalence, \% } \\
(95 \% \mathrm{Cl})\end{array}$ & \\
\hline \multicolumn{3}{|c|}{$n=15344^{*}$} & $n=1103739^{*}$ \\
\hline $\begin{array}{l}\text { Chronic kidney disease (based on } \\
\text { eGFR }<60 \mathrm{~mL} / \mathrm{min} \text { per } 1.73 \mathrm{~m}^{2} \text { ) }\end{array}$ & $2121(13.8)$ & 20.7 (19.9-21.5) & $202772(18.4)$ \\
\hline $\begin{array}{l}\text { End-stage kidney disease (based on } \\
\text { eGFR }<15 \mathrm{~mL} / \mathrm{min} \text { per } 1.73 \mathrm{~m}^{2} \text { ) }\end{array}$ & $113(0.7)$ & $0.8(0.7-1.0)$ & $3000(0.3)$ \\
\hline $\begin{array}{l}\text { Treatment for end-stage kidney } \\
\text { disease }\end{array}$ & \multicolumn{2}{|l|}{$n=21968$} & $n=1302177$ \\
\hline Receipt of kidney transplant & $67(0.3)$ & $0.4(0.3-0.5)$ & $2627(0.2)$ \\
\hline Receipt of long-term dialysis & $355(1.6)$ & $1.7(1.5-1.9)$ & $7161(0.5)$ \\
\hline $\begin{array}{l}\text { Risk of kidney-disease-related } \\
\text { adverse events (based on KDIGO) }\end{array}$ & \multicolumn{2}{|l|}{$n=10746 \dagger$} & $n=768569 \dagger$ \\
\hline Low $\ddagger$ & $6191(57.6)$ & $51.7(50.7-52.7)$ & 490934 (63.9) \\
\hline Moderately increased§ & $2642(24.6)$ & $25.3(24.4-26.3)$ & $163692(21.3)$ \\
\hline Highף & $1099(10.2)$ & $12.0(11.3-12.8)$ & $64250(8.4)$ \\
\hline Very high** & $814(7.6)$ & $10.8(10.0-11.5)$ & $49693(6.5)$ \\
\hline \multicolumn{4}{|c|}{ 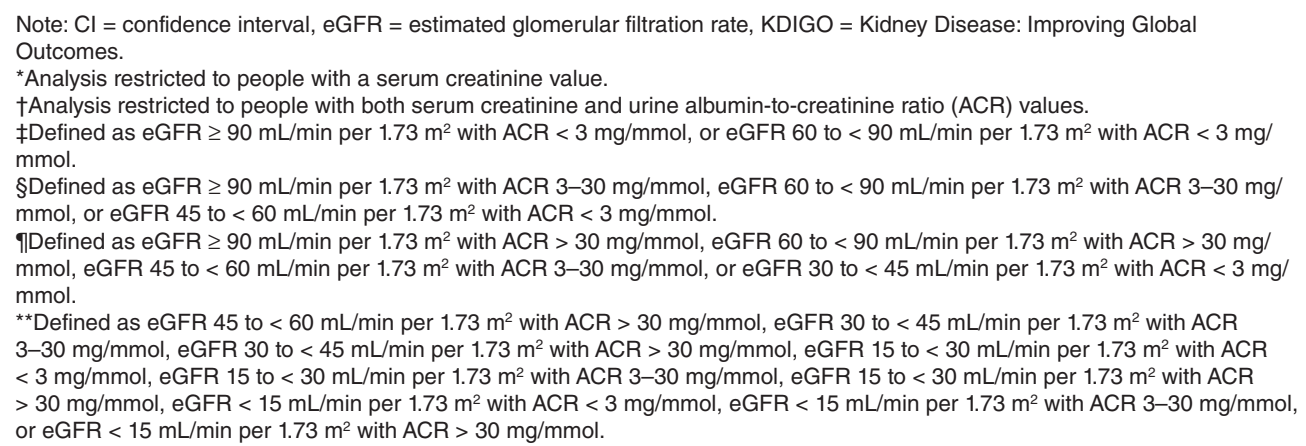 } \\
\hline
\end{tabular}

2 weeks $(89.9 \%$ of First Nations people v. $88.0 \%$ of other people in Ontario, $p=0.09$ ) (Table 3). In both groups, the majority (about $80 \%, p=0.09$ ) were also being prescribed an ACE inhibitor or an ARB, and most were not taking both concurrently. After initiation of ACE inhibitor or ARB therapy, serum potassium monitoring within the following 7-30 days was completed for similar proportions of First Nations people and other people in Ontario (17.4\% and 13.2\%, $p=0.4)$.

Access to nephrology care was similar for First Nations people and other people in Ontario. Of all patients who met nephrology referral criteria, about 20\% $(p=0.9)$ and $30 \%(p=$ 0.3 ) visited a nephrologist within the following 6 months and 1 year, respectively (Table 3 ).

\section{Interpretation}

Despite receiving similar quality of care for early-stage kidney disease, First Nations people with diabetes in Ontario were more likely than other Ontarians with diabetes to have endstage kidney disease and to start treatment at an earlier age. This may be due to other factors described previously, such as poor quality of diabetes care, food insecurity, physical inactivity and diabetes self-management barriers. ${ }^{21,22}$ Furthermore, the intergenerational impact of colonization among First Nations people may also have influenced the risk of end-stage kidney disease. ${ }^{23}$ In our study, the proportion receiving a kidney transplant was similar between the 2 populations, but, given the higher prevalence of long-term dialysis among First Nations people, this may signify lower transplantation access. In Alberta, researchers noted that First Nations people had transplantation referral rates similar to those of other Albertans but experienced barriers to completing the transplantation evaluation. ${ }^{24}$ Another potential barrier for access to endstage kidney disease therapy was that First Nations patients, on average, had to travel farther to receive dialysis, which has also been described in Saskatchewan. ${ }^{6}$ Since many First 


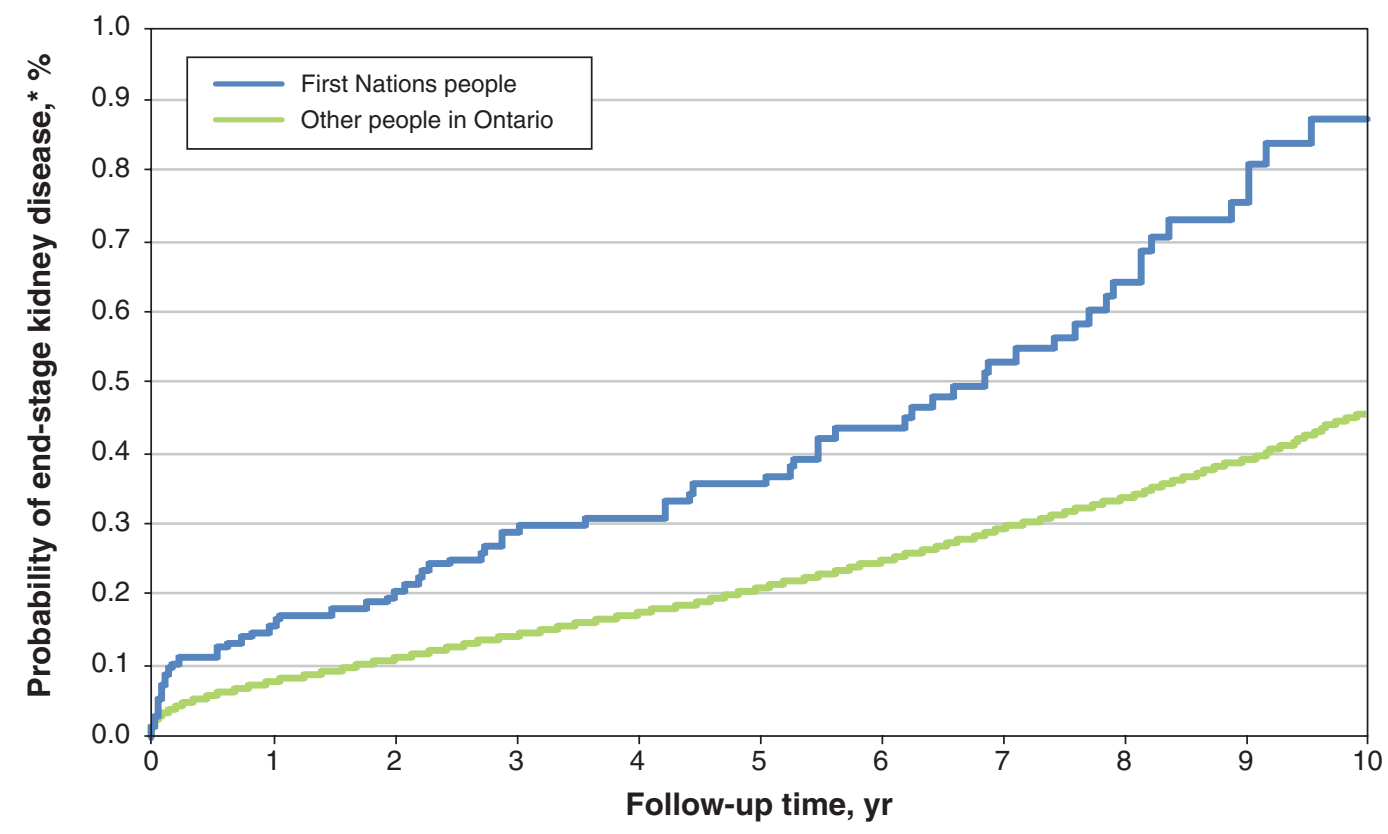

Figure 1: Probability of end-stage kidney disease following the diagnosis of diabetes among people who received the diagnosis between Apr. 1, 2002, and Mar. 31, 2014. ${ }^{*} y$ axis truncated at $1 \%$ as a result of the low probability of end-stage kidney disease.

Nations people in Ontario live in rural or remote locations ${ }^{13}$ and may need to relocate to larger cities to receive treatment, alternative therapies to in-centre hemodialysis, including home dialysis and kidney transplantation, could be used more. However, a previous study identified anxiety and financial reasons as barriers to peritoneal dialysis among First Nations people..$^{25} \mathrm{~A}$ large qualitative study among Indigenous people with end-stage kidney disease in Australia showed that, although the majority of patients had favourable opinions about kidney transplantation, many felt ill-informed about the process. ${ }^{26}$

Similar research has been conducted in Alberta and Saskatchewan. ${ }^{6,8,24}$ Our findings are consistent with research in Alberta, which showed that rates of end-stage kidney disease progression were 2-3 times higher for First Nations people than for other Albertans. ${ }^{8}$ Consistent with findings from Alberta and Saskatchewan, we found that First Nations people were more likely to receive in-centre hemodialysis (as opposed to home dialysis) than other people in Ontario. ${ }^{6,24}$ In regard to quality of care for early-stage kidney disease, patients in both populations were generally receiving recommended medications. This is consistent with other Canadian research showing high use of ACE inhibitors or ARBs, and statins for First Nations people with chronic kidney disease..$^{27,28} \mathrm{We}$ found that First Nations people were less likely than other people in Ontario to receive urine albumin-tocreatinine ratio tests to confirm or monitor their kidney disease. However, as noted in the following section, this was likely due to data limitations rather than a true care gap.
Further research is needed to better understand the factors contributing to the faster progression to end-stage kidney disease among First Nations people in Ontario and to help inform future interventions and policy initiatives.

\section{Limitations}

To identify chronic kidney disease prevalence, we used only the most recent serum creatinine and urine albumin-tocreatinine ratio values. In using only 1 value of each, it is possible that we may have misclassified patients into estimated glomerular filtration rate category or Kidney Disease: Improving Global Outcomes risk group. Some patients may have had acute kidney injury and not chronic kidney disease. Furthermore, we captured only people with outpatient laboratory tests between 2013 and 2015 in our data sources. Ontario hospitals started contributing laboratory results to an electronic repository at different times. ${ }^{29}$ One concern is that most hospitals in the North West Local Health Integration Network (where at least $25 \%$ of First Nations people in our study resided) did not start contributing until 2015. Therefore, we did not capture outpatient laboratory tests done at most local hospitals in this region. This limitation does not apply to the quality-of-care indicators, since we used fee-forservice billing codes to identify laboratory test completion. However, this method has its own limitations, as outpatient laboratory tests done in some hospitals may be covered under the hospital's global budget and not reimbursed through feefor-service billing. If First Nations people were more likely to 


\begin{tabular}{|c|c|c|c|}
\hline \multirow[b]{2}{*}{ Group; indicator } & \multicolumn{2}{|c|}{ No. $(\%)$ of people* } & \multirow[b]{2}{*}{$p$ value } \\
\hline & First Nations people & Other people in Ontario & \\
\hline \multicolumn{4}{|l|}{ Initial eGFR $<60 \mathrm{~mL} / \mathrm{min}$ per $1.73 \mathrm{~m}^{2}$} \\
\hline $\begin{array}{l}\text { Repeat outpatient serum creatinine test within } \\
6 \text { mo }\end{array}$ & $246 / 554(44.4)$ & $23371 / 50249(46.5)$ & 0.3 \\
\hline Outpatient ACR test within 6 mo & $100 / 554(18.0)$ & $11956 / 50249(23.8)$ & 0.001 \\
\hline \multicolumn{4}{|l|}{ Initial ACR $>3 \mathrm{mg} / \mathrm{mmol}$} \\
\hline Repeat outpatient ACR test within 6 mo & $312 / 2018(15.5)$ & 22 875/95 765 (23.9) & $<0.001$ \\
\hline \multicolumn{4}{|l|}{ Chronic kidney disease } \\
\hline $\begin{array}{l}\text { Outpatient serum creatinine test in following } \\
18 \mathrm{mo}\end{array}$ & $327 / 443(73.8)$ & $42740 / 53559(79.8)$ & 0.002 \\
\hline Outpatient ACR test in following $18 \mathrm{mo}$ & $182 / 443(41.1)$ & 26 797/53 559 (50.0) & $<0.001$ \\
\hline $\begin{array}{l}\text { Not prescribed an NSAID for longer than } 2 \text { wk } \\
\text { in following } 12 \text { mot }\end{array}$ & $772 / 859(89.9)$ & $111720 / 127008(88.0)$ & 0.09 \\
\hline $\begin{array}{l}\text { Not prescribed an ACE inhibitor and ARB } \\
\text { simultaneously in following } 12 \text { mo† }\end{array}$ & $840 / 859(97.8)$ & 125 536/127 $008(98.8)$ & 0.009 \\
\hline $\begin{array}{l}\text { ACE inhibitor or ARB prescription in following } \\
12 \text { mo† }\end{array}$ & $686 / 859(79.9)$ & 101 032/127 008 (79.5) & 0.9 \\
\hline Statin prescription in following 12 moł & $502 / 652(77.0)$ & $61667 / 77741(79.3)$ & 0.2 \\
\hline $\begin{array}{l}\text { Serum potassium test } 7-30 \mathrm{~d} \text { after initial ACE } \\
\text { inhibitor/ARB prescription } †\end{array}$ & $8 / 46(17.4)$ & $1134 / 8584(13.2)$ & 0.4 \\
\hline $\begin{array}{l}\text { Serum creatinine test } 7-30 \mathrm{~d} \text { after initial ACE } \\
\text { inhibitor/ARB prescription } \dagger\end{array}$ & $8 / 46(17.4)$ & $1298 / 8584(15.1)$ & 0.7 \\
\hline \multicolumn{4}{|c|}{ Initially meeting criteria for referral to nephrologist } \\
\hline $\begin{array}{l}\text { Visit to nephrologist within } 180 \mathrm{~d} \text { after referral } \\
\text { eligibility date }\end{array}$ & $136 / 672(20.2)$ & $5687 / 27611(20.6)$ & 0.9 \\
\hline $\begin{array}{l}\text { Visit to nephrologist within } 365 \mathrm{~d} \text { after referral } \\
\text { eligibility date }\end{array}$ & $170 / 545(31.2)$ & $6725 / 23210(29.0)$ & 0.3 \\
\hline \multicolumn{4}{|c|}{$\begin{array}{l}\text { Note: } \mathrm{ACE}=\text { angiotensin-converting enzyme, } \mathrm{ACR}=\text { albumin-to-creatinine ratio, } \mathrm{ARB}=\text { angiotensin II receptor blocker, eGFR = estimated } \\
\text { glomerular filtration rate, NSAID = nonsteroidal anti-inflammatory drug. } \\
\text { "The number of people in the denominators/subcohorts for each indicator varied based on the amount of look-forward period needed to } \\
\text { assess the indicator. For example, indicators requiring } 18 \text { months of follow-up time included eligible patients with laboratory values to } \\
\text { define the subcohorts on or before Mar. } 30,2014 \text {, with follow-up to Sept. } 30,2015 \text {; indicators that required only 1-year follow-up included } \\
\text { eligible patients with laboratory values to define the subcohorts on or before Sept. 30, 2014, with follow-up to Sept. 30, 2015. } \\
\text { †Only among people } 65 \text { years of age or more. } \\
\text { fOnly among people } 65-80 \text { years of age. }\end{array}$} \\
\hline
\end{tabular}

receive outpatient laboratory tests at these hospitals than other people in Ontario, this could partly explain the lower proportion who received tests to confirm or monitor their kidney function. Finally, prescription medication information in our data sources was available only for people aged 65 years or more. Therefore, the medication use quality indicators are not generalizable to people younger than 65 . Other limitations of the general study design and data sources have been published elsewhere. ${ }^{13}$

\section{Conclusion}

First Nations people with diabetes in Ontario were 3 times more likely to have end-stage kidney disease, with an earlier onset, than other people with diabetes in Ontario despite receiving similar quality of care for early-stage kidney disease. They were also less likely to receive home dialysis therapy and more likely to travel farther to receive in-centre dialysis treatment. Policy initiatives should focus on community-based support and interventions to minimize the risk and burden of kidney disease in First Nations people.

\section{References}

1. Pelletier C, Dai S, Roberts K, et al. Report summary. Diabetes in Canada: facts and figures from a public health perspective. Chronic Dis Inj Can 2012;33:53-4.

2. Kiberd BA, Clase CM. Cumulative risk for developing end-stage renal disease in the US population. 7 Am Soc Nephrol 2002;13:1635-44.

3. Annual statistics on organ replacement in Canada: dialysis, transplantation and donation, 2007 to 2016. Ottawa: Canadian Institute for Health Information; 2017. Available: www.cihi.ca/sites/default/files/document/corr_ar-snapshot-en.pdf (accessed 2019 June 21).

4. Ontario Renal Plan II: 2015-2019. Toronto: Ontario Renal Network; 2015. Available: www.ontariorenalnetwork.ca/sites/renalnetwork/files/assets/ ontariorenalplan2.pdf (accessed 2019 June 21).

5. Gao S, Manns BJ, Culleton BF, et al.; Alberta Kidney Disease Network. Prevalence of chronic kidney disease and survival among Aboriginal people. $7 \mathrm{Am} \mathrm{Soc}$ Nephrol 2007;18:2953-9. 
6. Thomas DA, Huang A, McCarron MCE, et al. A retrospective study of chronic kidney disease burden in Saskatchewan's First Nations people. Can 7 Kidney Health Dis 2018;5:2054358118799689.

7. Jiang Y, Osgood N, Lim HJ, et al. Differential mortality and the excess burden of end-stage renal disease among First Nations people with diabetes mellitus: a competing-risks analysis. CMA7 2014;186:103-9.

8. Samuel SM, Palacios-Derflingher L, Tonelli M, et al. Association between First Nations ethnicity and progression to kidney failure by presence and severity of albuminuria. CMA7 2014;186:E86-94

9. Benchimol EI, Smeeth L, Guttmann A, et al.; RECORD Working Committee. The REporting of studies Conducted using Observational Routinely-collected health Data (RECORD) statement. PLoS Med 2015;12:e1001885.

10. First Nations Information Governance Centre. The First Nations principles of OCAP. Available: https://fnigc.ca/ocapr.html (accessed 2019 Feb. 26).

11. Indian Act, RSC 1985, c I-5. Available: https://laws-lois.justice.gc.ca/eng/ acts/i-5/ (accessed 2019 Sept. 19).

12. Walker JD, Rowe R, Jones CR. Describing the process of ethical conduct of research in an Ontario-wide First Nations diabetes research project. CMAJ 2018;190(Suppl):S19-20.

13. Slater M, Green ME, Shah B, et al. First Nations people with diabetes in Ontario: methods for a longitudinal population-based cohort study. CMAF Open 2019;4:E680-8.

14. Levey AS, Stevens LA, Schmid CH, et al. CKD-EPI (Chronic Kidney Disease Epidemiology Collaboration). A new equation to estimate glomerular filtration rate [published erratum in Ann Intern Med 2011;155:408]. Ann Intern Med 2009; 150:604-12.

15. 2011 National Household Survey: data tables. Cat no 99-010-X2011036. Ottawa: Statistics Canada; 2011, modified 2019 Jan. 23. Available: www12. statcan.gc.ca/nhs-enm/2011/dp-pd/dt-td/Rp-eng.cfm?LANG=E\&APATH=3\& DETAIL $=0 \& D I M=0 \& F L=A \& F R E E=0 \& G C=0 \& G I D=0 \& G K=0 \& G R P=0 \& P I D$ $=107647 \& \mathrm{PRID}=0 \& \mathrm{PTYPE}=105277 \& \mathrm{~S}=0 \& \mathrm{SHOWALL}=0 \& \mathrm{SUB}=0 \&$ Temporal $=2013 \&$ THEME $=95 \& \mathrm{VID}=0 \& \mathrm{VNAMEE}=\& \mathrm{VNAMEF}=($ accessed $2018 \mathrm{July} 17)$.

16. KDIGO 2012 clinical practice guideline for the evaluation and management of chronic kidney disease. Kidney Int Suppl 2013;3:1-150.

17. Tu K, Bevan L, Hunter K, et al. Quality indicators for the detection and management of chronic kidney disease in primary care in Canada derived from a modified Delphi panel approach. CMA7 Open 2017;5:E74-81.

18. Referral guidance: KidneyWise Clinical Toolkit. Toronto: Ontario Renal Network; 2018. Available: www.ontariorenalnetwork.ca/en/kidney-care-resources/ clinical-tools/primary-care-tools/kidneywise-contact-info (accessed 2019 Feb. 28).

19. Fay MP, Feuer EJ. Confidence intervals for directly standardized rates: a method based on the gamma distribution. Stat Med 1997;16:791-801.

20. Anderson RN, Rosenberg HM. Age standardization of death rates: implementation of the year 2000 standard. Natl Vital Stat Rep 1998:47:1-16, 20.

21. Kulhawy-Wibe S, King-Shier KM, Barnabe C, et al. Exploring structural barriers to diabetes self-management in Alberta First Nations communities. Diabetol Metab Syndr 2018;10:87.

22. Green ME, Jones CR, Walker JD, et al., editors. First Nations and diabetes in Ontario. Toronto: ICES; 2019.

23. Greenwood M, de Leeuw S, Lindsay NM, et al., editors. Determinants of Indigenous peoples' bealth in Canada: beyond the social. Toronto: Canadian Scholars' Press; 2015.

24. Tonelli M, Chou S, Gourishankar S, et al.; Alberta Kidney Disease Network. Wait-listing for kidney transplantation among Aboriginal hemodialysis patients. Am 7 Kidney Dis 2005;46:1117-23.

25. Mathew AT, Park J, Sachdeva M, et al. Barriers to peritoneal dialysis in Aboriginal patients. Can 7 Kidney Health Dis 2018;5:2054358117747261.

26. Devitt J, Anderson K, Cunningham J, et al. Difficult conversations: Australian Indigenous patients' views on kidney transplantation. BMC Nephrol 2017;18:310.

27. Harris SB, Naqshbandi M, Bhattacharyya O, et al.; CIRCLE Study Group. Major gaps in diabetes clinical care among Canada's First Nations: results of the CIRCLE study. Diabetes Res Clin Pract 2011;92:272-9.

28. Patapas JM, Blanchard AC, Iqbal S, et al. Management of Aboriginal and nonAboriginal people with chronic kidney disease in Quebec: quality-of-care indicators. Can Fam Physician 2012;58:e107-11.

29. Lab results. Toronto: eHealth Ontario; 2018. Available: www.ehealthontario. on.ca/for-healthcare-professionals/ontario-laboratories-information-system-olis (accessed 2018 July 18).

Affiliations: ICES Western (Nash, Dirk, McArthur, Garg); Department of Epidemiology and Biostatistics (Nash), Western University, London Ont.; ICES Central (Shah, Walker), Toronto, Ont.; Department of Infectious Diseases (Dirk), Nova Scotia Health Authority, Halifax, NS;
ICES Queen's (Green); Department of Family Medicine (Green), Queen's University, Kingston, Ont.; Department of Medicine (Shah), University of Toronto, Toronto, Ont.; School of Rural and Northern Health (Walker), Laurentian University, Sudbury, Ont.; Patient and Family Advisory Council (Beaucage), Ontario Renal Network; the Chiefs of Ontario (Jones), Toronto, Ont.; Department of Medicine (Garg), Western University, London, Ont.

Contributors: Michael Green, Baiju Shah, Jennifer Walker and Carmen Jones conceived the study. Amit Garg and Danielle Nash designed the study, with contributions from Jade Dirk, Eric McArthur, Michael Green, Baiju Shah, Jennifer Walker, Mary Beaucage and Carmen Jones. Mary Beaucage provided advice on the study design based on her lived experience with kidney disease. Jennifer Walker, Mary Beaucage and Carmen Jones provided input regarding First Nations research principles. Danielle Nash, Jade Dirk and Amit Garg developed the study protocol, and Eric McArthur, Michael Green, Baiju Shah, Jennifer Walker, Mary Beaucage and Carmen Jones reviewed it. Eric McArthur analyzed the data. Danielle Nash, Jade Dirk and Amit Garg drafted the manuscript. All of the authors critically revised the manuscript for important intellectual content, approved the final version to be published and agreed to be accountable for all aspects of the work.

Funding: This study was supported by ICES, which is funded by an annual grant from the Ontario Ministry of Health and Long-Term Care (MOHLTC). The study was completed at the ICES Western site, where core funding is provided by the Academic Medical Organization of Southwestern Ontario, the Schulich School of Medicine and Dentistry, Western University, and the Lawson Health Research Institute. The research was conducted by members of the ICES Kidney, Dialysis and Transplantation team at the ICES Western facility, who are supported by grant FDN-138377 from the Canadian Institutes of Health Research (CIHR). This study received funding from an IMPACT Award from the Ontario SPOR SUPPORT Unit. Additional support was provided to Michael Green through the Brian Hennen Chair in Family Medicine, Queen's University, to Jennifer Walker through a Tier 2 Canada Research Chair in Indigenous Health, and to Amit Garg through the Dr. Adam Linton Chair in Kidney Health Analytics, Western University and a Clinician Investigator Award from CIHR.

Acknowledgements: The authors thank their partner, the Chiefs of Ontario, whose contributions throughout all stages of the study were pivotal to the success and quality of the project. They also thank the members of the Patient Advisory Committee for providing insightful and thoughtful input to this project and IMS Brogan for use of their Drug Information Database.

Disclaimer: Parts of this material are based on data and/or information compiled and provided by the Ontario Ministry of Health and LongTerm Care (MOHLTC), the Canadian Institute for Health Information and the Chiefs of Ontario. This study was supported by ICES, which is funded by an annual grant from the MOHLTC. The opinions, results and conclusions reported in this article are those of the authors and are independent from the funding and data sources. No endorsement by ICES or the Ontario MOHLTC is intended or should be inferred.

Supplemental information: For reviewer comments and the original submission of this manuscript, please see www.cmajopen.ca/content/7/4/ E706/suppl/DC1. The data set from this study is held securely in coded form at ICES. Although data-sharing agreements prohibit ICES from making the data set publicly available, access can be granted to those who meet prespecified criteria for confidential access, available at www.ices. on.ca/DAS. The full data set creation plan and underlying analytic code are available from the authors on request, with the understanding that the programs may rely on coding templates or macros that are unique to ICES and are therefore inaccessible or may require modification. 